\title{
Evaluation of the risk of corneal ectasia
}

\author{
Nikolai M Sergienko* and Iryna V Shargorodska \\ Department of ophthalmology, National Medical Academy of Postgraduate Education, Kiev, Ukraine
}

\begin{abstract}
Objective: LASIK is associated with a severe complication known as corneal ectasia. A direct evaluation of the biomechanical corneal property may be performed to select patients for excimer laser surgery.

Methods: Detection of the biomechanical corneal properties was performed using a specific device known to produce short intraocular pressure elevation (IOP) at approximately $20 \mathrm{~mm} \mathrm{Hg}$. The cornea topographic method was performed twice: before and during IOP loading.

Results: The patient, a 26-year-old female with myopia of both eyes, requested surgical correction of her myopia. IOP loading had caused extension and deformation of the cornea shape of both eyes. Normal eyes retain their shape under such conditions.

We classified the biomechanical properties of both corneas as very weak and recommended the patient refrain from refractive surgery.

Conclusions: Direct evaluation of the corneal biomechanical properties revealed potential in the selection of patients for excimer laser surgery.
\end{abstract}

\section{Introduction}

Laser in situ keratomileusis (LASIK) has become the gold standard in refractive surgery. After undergoing LASIK, pilots have begun to return to flight status in the United States [1]. Nevertheless, LASIK is associated with a severe complication known as corneal ectasia. This complication is of serious concern because patients undergo LASIK surgery with practically healthy eyes and have other options for vision correction. The methods used to estimate the risk of post-surgical ectasia have been well documented in the literature [2-4]. Despite good ability to predict this complication, current studies continue to report cases of iatrogenic keratectasia $[5,6]$.

Here, we developed a new method, which is intended to evaluate a dynamic change of cornea shape under a condition of artificially elevated intraocular pressure (IOP) [7]. Distortion of the cornea occurs in case of a weakened corneal biomechanical property. The principle of ophthalmodinamometer (ODM) was applied. However, ODM causes meridional eyeball deformation, resulting in corneal astigmatism. Our instrument induces pressure via the circle element in the eyeball area behind the limbus. Such an approach enables the initial corneal shape to be secured. The stability of the cornea shape or its deformation serves as a basis for an evaluation of the cornea biomechanical property.

The reported case presents the first attempt to use our method of direct examination of the corneal biomechanical property to indicate or contraindicate patients for excimer laser surgery.

\section{Case description}

The patient, a 26-year-old female with myopia of both eyes, requested surgical correction of her myopia. She received an invitation to undergo the surgical correction at a private clinic. The patient provided her informed consent on the examination.

In addition to an anomaly of refraction, the patient's medical history was unremarkable. At the time of examination, the manifest refractions were -7.0 and -7.5 diopters of the right and left eyes, respectively, and the corrected distance visual acuity (CDVA) was $20 / 20$ for both eyes. The keratometric readings were 43.5/44.0 diopters and 44.0/44.75 diopters, the central corneal thickness were $505 \mu \mathrm{m}$ and $496 \mu \mathrm{m}$, and optical axial lengths were $26.68 \mathrm{~mm}$ and $26.74 \mathrm{~mm}$ in the right and left eyes, respectively.

Using our method, the first step of the examination was to obtain tomographic maps of the cornea (Wavelight-Allegro Analyzer). Next, $30 \mathrm{~g}$ of pressure was applied. Under elevated IOP, a tomographic map was obtained a second time.

Prior to the procedure, neither of the eyes displayed features indicating keratoconus adherence, and both eyes appeared negative with regard to the risk for ectasia. The tomographic data were similar to and consistent with those of normal corneas. As shown in Figure 1, the left image represents a cornea of the right eye. A central corneal thickness of approximately $500 \mu \mathrm{m}$ is considered normal. Keratometry readings did not exceed $45.0 \mathrm{D}$, and there were no paracentral or midperipheral zones of corneal thickening.

Under artificially elevated IOP conditions, striking changes occurred in both eyes (Figure 1, middle). The entire corneal surface of both eyes appeared to have cornea distortion with an irregular pattern. Different degrees of corneal thickness, which are not typical for keratoconus, also appeared in different areas. A usual response of normal eyes on IOP loading is shown in Figure 2, which was obtained

Correspondence to: Nikolai Sergienko, Eye Microsurgery Center, Komarov ave, 3, Kyiv, 03680, Ukraine, Tel: +38050 6886428, +38044 4080536; Fax: +38044 4044485; E-mail: nmsmicro@gmail.com

Key words: corneal ectasia, biomechanical property, eximer-laser surgery

Received: January 18, 2016; Accepted: February 05, 2016; Published: February 10,2016 


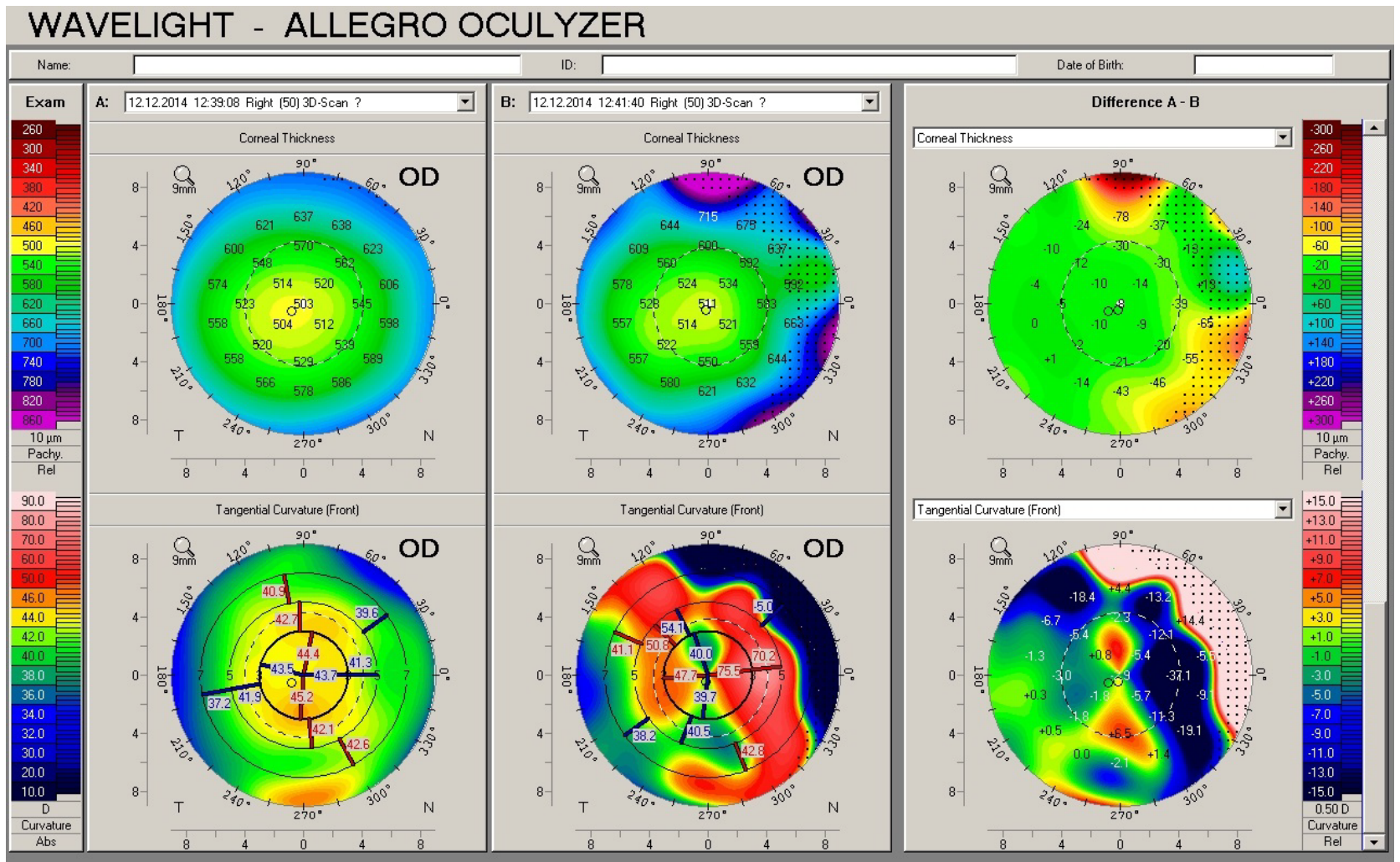

Figure 1. Corneal topography data of the eye with myopia $6.5 \mathrm{D}$ : left- initial state of cornea, middle - irregular cornea distortion during IOP elevation and right - difference between the 2 examinations.

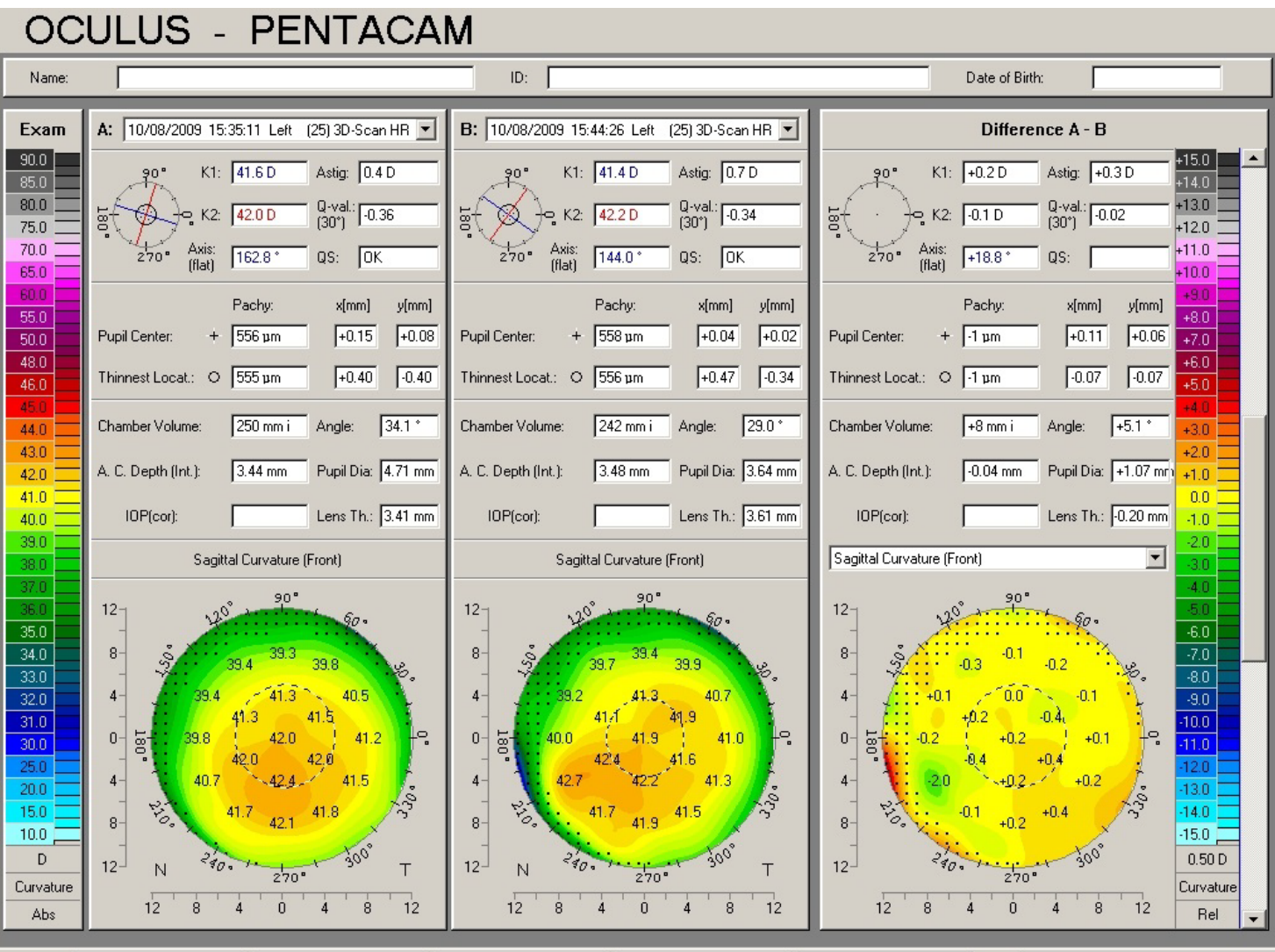

Figure 2. Corneal topography data of emmetropic eyes with negligible difference in cornea shape before and during IOP loading: initial state of the cornea, an alteration during loading and difference between the 2 measurements. 
from our previous study. Thus, we classified the biomechanical properties of both corneas as very weak.

\section{Discussion}

During patient selection for excimer laser surgery, an indirect measure of the cornea state was used to obtain parameters, including cornea thickness, curvature of its anterior surface, and relationship between the anterior and posterior cornea curvatures. This approach is useful but not sufficient for patient selection. Despite the application of an indirect evaluation of the cornea biomechanical property, there have been numerous reports on severe complications, such as postoperative keratectasia. A prediction of the complication is difficult to perform because there is a convincing experience of successful refractive surgery correction of myopia over 10.0 diopters with a corneal thickness 488 $580 \mu \mathrm{m}$. Moreover, ectasia can occur in the eye with a corneal thickness of $597 \mu \mathrm{m}$ [8].

The Ocular Response Analyzer (ORA) for the objective measurement of corneal biomechanical properties has shown great promise in the field [9]. However, its capacity is limited because it has access to only the central corneal area. In addition, the resulting measurements are heavily dependent on the IOP $[10,11]$.

Why do we use the IOP as the approach for loading? There are convincing arguments that the cornea shape is dependent on two factors: the IOP and the cornea biomechanical property [12]. In our method, cornea distortion occurred as a consequence of the inability of the weak corneal tissue to resist IOP elevation. The mechanical factor of the distortion using the instrument should undoubtedly be excluded. Unlike ODM, our device induces pressure on the eyeball using a circle element that places equal loading at all meridians. Thus, the eyes of the patient failed to maintain their natural cornea shape exclusively due to the local weak biomechanical property of the cornea. Previous experiences using our device on 50 eyes with refraction within hyperopia $0.5 \mathrm{D}$ - myopia $0.5 \mathrm{D}$ have demonstrated that normal eyes successfully retained their corneal curvature under conditions of IOP increases of approximately $20 \mathrm{~mm} \mathrm{Hg}$ [7].

In the reported case, we recommended our young patient to refrain from the surgery due to the risk of keratectasia. Correction of myopia of $6.5 \mathrm{D}$ would require an elimination of approximately $80 \mu \mathrm{m}$ of the cornea layer, which will inevitably weaken the cornea and threaten the patient with ectasia under action of a normal IOP.

The cornea thickness around $500 \mu \mathrm{m}$ belongs to a borderline for a possible correction of the high degree myopia. In current literature there are numerous papers presenting a successful eximer-laser correction in such cases. At the same time the keratectasia sometimes occurs in eyes with a thick cornea. It is important to stress that postoperative behaviour of the cornea depends entirely on the cornea biomechanical properties. In order to avoid this complication with guarantee the cornea biomechanical property should be measured in all cases, but especially in eyes with the cornea thickness $500 \mu \mathrm{m}$ or less and in case of a keratoconus suspicion.
If the myopia was under $3.0 \mathrm{D}$, then PRK could be recommended but without any guarantee. We understand that our initial experience cannot completely resolve a series of questions. For instance, what method of excimer laser correction is best in individual cases, what degree of myopia may be included in the treatment protocol, and how does the surgery affect cornea hysteresis? These issues and other issues should be investigated, and this first experience motivates further studies.

Our paper is based on examination of only one patient and therefore we defined it as a case report. This paper should be considered as attachment to the recently published article [7] which reflexes the issue more profoundly.

\section{Conclusion}

Our novel method is based on loading with elevated IOP, which revealed distinct weaknesses of the corneal tissue of a patient with a high degree myopia. Due to the potential risk of postoperative corneal keratectasia, the patient was recommended to refrain from excimer laser correction of the myopia.

\section{References}

1. Tanzer DJ, Brunstetter T, Zeber R, Hofmeister E, Kaupp S, et al. (2013) Laser in situ keratomileas8is in United States Naval aviators. J Cataract Refract Surg 39: 10471058. [Crossref]

2. McMonnies CW (2014) Screening for keratoconus suspects among candidates for refractive surgery. Clin Exp Optom 97: 492-498. [Crossref]

3. Montalban R, Alio JL,Javaloy J, Pinero DP (2013) Comparative analysis of the relationship between anterior and posterior corneal shape analyzed by Scheimpflug photography in normal and keratoconus eyes. Graefe's Arch Clinical Exper Ophthalmol 251: 1547-1555. [Crossref]

4. Saad A, Ganitel D (2010) Topographic and tomographic properties of formefrustekeratoconus corneas. Invest Ophthalmol Vis Sci 51: 5546-5555.[Crossref]

5. Seitz B, Rozsíval P, Feuermannova A, Langenbucher A, Naumann GO (2003) Penetrating keratoiplasty for iatrogenic keratoconus after repeat myopic laser in situ keratomileusis: histologic findings and literature review.J Cataract Refract Surg 29: 2217-2224.[Crossref]

6. Woodward MA, Randleman JB, Russell B, Lynn MJ, Ward MA, et al. (2008) Visua rehabilitation and outcomes for ectasia after corneal refractive surgery. $J$ Cataract Refract Surg 34: 383-388.[Crossref]

7. Sergienko NM, Shargorodska IV (2014) Corneal Biomechanical Property Measurement with an IOP Loading Method in Keratoconic Patients. Curr Eye Res 39: 994-999. [Crossref]

8. Magallanes R, Shah S, Zadok D, Chayet AS, Assil KK, et al.(2001) Stability after laser in situ keratomileusis in moderately and extremely myopic eyes. J Cataract Refract Surg 27: 1007-1012. [Crossref]

9. Luce DA (2005) Determining in vivo biomechanical properties of the cornea with the ocular response analyzer. J Cataract Refract Surg 31: 156-162. [Crossref]

10. McMonnies CW (2012) Assessing corneal hysteresis using the ocular response analyzer. Optom Vis Sci 89: 343-349.[Crossref]

11. Sergienko NM, Shargorodska I (2009) Determining corneal hysteresis and preexisting intraocular pressure. J Cataract Refract Surg 35: 2033-2034. [Crossref]

12. McMonnies CW (2013) The possible significance of the baropathic nature of keratectasia. Clin Exp Optom 96: 197-200.[Crossref]

Copyright: (2016 Sergienko NM. This is an open-access article distributed under the terms of the Creative Commons Attribution License, which permits unrestricted use, distribution, and reproduction in any medium, provided the original author and source are credited. 